\title{
Persuasive technology for enhanced learning behavior in higher education
}

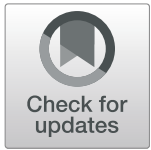

\author{
Yohana Dewi Lulu Widyasari ${ }^{1,2}$, Lukito Edi Nugroho ${ }^{1 *}$ and Adhistya Erna Permanasari ${ }^{1}$
}

\footnotetext{
* Correspondence: lukito@ugm.ac.id Article submitted to: International Journal of Educational Technology in Higher Education.

${ }^{1}$ Electrical and Information

Technology Engineering Departement, Universitas Gadjah

Mada, Yogyakarta 55281, Indonesia Full list of author information is available at the end of the article
}

\begin{abstract}
Obtaining quality learning behavior requires constant improvement. The development of learning methods often unsupported changes in the behavior of participants. This condition causes reluctance to use new learning methods by some users. Meanwhile, technological developments, especially Web 2.0, have the ability to change the way people communicate and interact. This study used the features and capabilities of Web 2.0 to improve learning behavior. The use of this technology will be adjusted with learning methods, especially online-learning that overgrows nowadays. The concept of an integrated system applied a persuasive strategy to bring persuasion. Modifications elearning were done by combining the concepts of Web 2.0 and persuasive system. Tests were performed on aspects that affect the user's intentions by comparing the initial and final conditions after the intervention. The behavior changes were expected to improve user involvement and intention in online learning. The results show that the modified technology by using persuasive concept can improve the users' intention.
\end{abstract}

Keywords: Persuasive technology, E-learning, Technology web 2.0, Intervention, Learning behavior

\section{Introduction}

The teaching and learning process is a business process of educational organizations. The success of this process obtained if the chosen strategy accepted by the members of the organization (Zeng, Gonzalez, \& Lobato, 2015). This acceptance including the choice of technology which is supporting the teaching and learning so that it can bring influence the changes to the learning behavior of its users. An individual learning culture is related to maximizing the sustainability of technology use. The development of Internet-based communication technology can alter the custom learners communicates and interacts. Some examples of Web 2.0 based technologies are application blogs, social media, YouTube and others (Newman, Chang, Walters, \& Wills, 2016). Communication and interaction activities carried out with Web 2.0 technology would provide an opportunity to be developed into persuasion technology that can shape and improve existing behavior.

In a learning culture using technology, the process of behavior change is influenced by the use of technology by its users (Batsila, Tsihouridis, Vavougios, \& Ioannidis, 2015). All participants do not always accept the method of learning using new technology. User involvement is essential in this technology. This study used the ability of Web 2.0 technology to build communication and interaction so that it helps to improve learning behavior; therefore, it can be used to support online learning methods that are rapidly developing recently.

(c) The Author(s). 2019 Open Access This article is distributed under the terms of the Creative Commons Attribution 4.0 International License (http://creativecommons.org/licenses/by/4.0/), which permits unrestricted use, distribution, and reproduction in any medium, provided you give appropriate credit to the original author(s) and the source, provide a link to the Creative Commons license, and indicate if changes were made. 
A person's interest in this technology can be demonstrated by a high intention of Web 2.0-based technologies. A lot of knowledge, information, and influence are carried indirectly when someone uses this technology (Gavin, Baxter, Baxter, \& Connolly, 2014). A person's interest in digital learning is also essential to achieve better learning outcomes. There is a gap in the level of interest between users of Web 2.0 technology and existing e-learning technologies. This difference requires an approach and understanding so that the e-learning technology can be used in a better role.

This study was developed based on the problems arising from the massive use of Web 2.0 and the demands of e-learning technology users in the learning process. Refer to this situation, and it is necessary to change digital learning behavior that has a high level of interest. Therefore, a model is needed to help intervened the behavior of e-learning users from the initial behavior to the target behavior. Then, modification of the Web 2.0-based e-learning technology is needed to run the model to bring more changes in the behavior of its users.

Online learning behavior was the special focus of this study, although the concepts presented can be used in other individual behaviors. This study used the ability of Web 2.0 technology to help improve learning behavior; therefore, it can be used to support online learning methods that are rapidly developing recently. The concept of a persuasive system was used as a strategy for persuasion. Modifications to e-learning technology were carried out by combining the concepts of Web 2.0 and persuasion systems. Testing was done on aspects that affect the user's intention by comparing the initial and final conditions after using the technology. The research structure is shown as follows: The overview of the persuasion system, e-learning, and Web 2.0 technology is described in Chapter 2. Chapter 3 explains the research methodology. While Chapter 4 shows the analysis of the findings and discussion. Lastly, the conclusion is given in Chapter 5.

\section{Overview of persuasive system, e-learning, and technology web $\mathbf{2 . 0}$ Persuasive system}

Information system had potentially utilized to predispose its consumers in improving and changing human behavior in several methods (Fogg, 2009). The change of behavior and attitudes which is caused by interactive technology can be categorized as persuasive technology. A persuasive concept should be customized with the goal and distribution of messages, and also computer technology adoption. The growth of the social web in composing, collaborating, and distributing information will bring opportunities this technology to affect its user behavior.

A persuasive system is defined as computer software or information system designed to reinforce alteration or improve attitudes, behavior, or both without coercion and deception. Persuasive system design developed in (Oinas-Kukkonen \& Harjumaa, 2009) has three main stages. The first stage is essential, which is the stage that involves an understanding of the basic problems that become the background to a persuasive system before implementing it. In the second stage, matters related to the context of the persuasive system are discussed.

Contexts at this stage include intent as well as event and strategy used in persuasive systems. The context of intent consists of the type of change and persuader. The event includes the context of use, the context of the person using it and the context of the technology used as the media. The strategy context must be distinguished from the message and the type of delivery. The last stage is the system qualities for a new technology designed as a persuasive system and system qualities to evaluate the features of an existing system. 
The system qualities are the last stage. Its use to evaluate the features of an existing system. This stage focuses are primary task and dialogue support, support for the credibility of the system, and also social support. (Oinas-Kukkonen \& Harjumaa, 2009).

\section{E-learning and web 2.0}

The development of Web 2.0 technology encourages the latest e-learning transformation from a centralized and traditional education system to an interactive and communicative online learning system (Gavin et al., 2014). Web 2.0 technology brings its social aspects in the traditional learning process. Web 2.0 is considered as a new type of technology that is increasingly being used and integrated with e-learning applications for developing active knowledge and sharing in communities or study groups.

Similar to the Web 2.0 paradigm, the term of e-Learning 2.0 (Chua \& Tay, 2012) described a bottom-up approach to the learning process and based on user-generated learning content. The uses of web 2.0 features in the learning context is driven by user participation. This ecosystem has been described as Learning 2.0 (Inamorato dos Santos \& Punie, 2016; Kim \& Kim, 2016). Davis (2005) states that the concept of Web 2.0 is related with attitude and not only the technology because it directs back to an original web, but user participation is encouraged and make a social network. The openness in the network automatically affects the whole learning process.

The use of e-learning in the learning objectives is expected to have the same outcome, both in the education and organizational environment. The definition of the word 'learning' is an attempt made to obtain intelligence or effort to change behavior in response to something. The features of Web 2.0 technology that are used include communication, collaboration, participation, and connection (Davis, 2005). Web 2.0-based e-learning application provides a menu for communication in the form of the chat-room for the teachers and between the students. This feature is called synchronous communication. The communication feature is also presented asynchronously in the form of e-mail and discussion forum. The collaboration feature is done by presenting the opportunity for all users to be able to share even though class limits them.

The technology Web 2.0: Web 2.0 is a social software technology form that drives its users to get their objective. Infrastructure and organizational culture affect the use of web 2.0 technology. Organizational, technical and social aspects are things that need to be considered in the strategy of using web 2.0. In other studies, the web 2.0 is used to encourage the adoption of technology (Mitra \& Roy, 2016), as a communication medium and encourage a change of communication method (Kim, 2017), and provide positive effects on the process learning for an individual, group, and organizational.

Web 2.0 technology can improve the ability to communicate, collaborate, and share (Shipps, 2013) and also encourages innovations (Zeng et al., 2015). Factors affecting the use of Web 2.0 technology include social factors and the culture of the workplace (Gavin et al., 2014), users' adoption and acceptance (Napitupulu, 2017), internal organizational factors (infrastructures and organizational cultures); uniqueness, size, type, and the culture of an organization (Gavin et al., 2014); cultural, technical, and organizational factors.

Web 2.0 is a technology that has social concepts. This technology uses interactive concepts, dynamic, has irregular structures content and provides full control to the user. Some researchers underline that Web 2.0 technology can bring a positive effect on aspects of individuals, groups, organizational learning and build knowledge that is easy and always 
available to the organization (Anderson, 2012; Newman et al., 2016; Sivarajah, Irani, \& Weerakkody, 2015). Web 2.0 technology also supports collaboration, communication, and participation. Organizational employees are possible to share knowledge or idea trough web 2.0 with other employees. The sharing process can improve the organization's innovation. Also, it encourages the process of building an organizational knowledge database in the repository (Batsila et al., 2015; Zeng et al., 2015).

Web 2.0 is social technology that can construct relationships and develop persuasion among users. The ability of web 2.0 in observation, affiliation, and access can encourage social comparison, social learning, and normative influence between users. Web 2.0 is the second generation of web-resolution that allows users to build and publish content as well as do collective intelligence; thus, it can be called a social web generation. The aspects of connection, communication, participation, and collaboration are characteristics of Web 2.0 that will be used in intervening in the way the organization works. The potentiality of Web 2.0 as a carrier of social features enables the intervention process to be carried out with this technology.

The development of information technology has an impact on the learning process. E-learning technology is becoming a new paradigm of modern education. The use of e-learning is not only a learning aid but also can change the existing learning culture. The nature of the flexibility to be able to access, do just-in-time deployment, the level of effectiveness and the costs that must be provided from the use of e-learning has encouraged the adoption of this technology in many organizations (Admiraal \& Lockhorst, 2009).

On the other hand, with the advent of web 2.0, such as Blogs, Wikis, YouTube or SNS, it has led to the transformation of the learning process (Yadav, Tiruwa, \& Suri, 2017). Integration of the latest learning technology or e-learning from a centralized and traditional education system to an interactive and communicative online learning system. Web 2.0 as a social web can encourage the learning of social constructivism, connectivism, distributed cognition, situated learning, and collective intelligence (Simoes \& Borges Gouveia, 2008). E-learning encourages users to be more active and participatory without having to meet face to face. The knowledge and information shared in e-learning can be easily traced compared to those obtained directly.

Web 2.0 carries the social aspects it has in the traditional learning process where communication between teachers and students is also established among fellow students. Web 2.0 is considered as a type of new technology that is increasingly being used and integrated with e-learning applications for active knowledge creation and sharing in communities or study groups (Mason \& Rennie, 2007). The application of e-learning in the educational environment is different from the organizational environment in general because it requires conformity with the goals and needs of the organization itself (Wang, 2011).

By the web 2.0 paradigm, the term e-Learning 2.0 (Chua \& Tay, 2012) has evolved to describe the bottom-up approach to the learning process, decentralized and to user-generated learning content. The use of web 2.0 features for participatory communities of learners and learning ecosystems has been described as Learning 2.0 (Seely Brown \& Adler, 2008). Davis (2005) explains that the concept of web 2.0 is attitude and not technology because it directs the web back to its creator, where user participation is encouraged and is a socially open network. Social openness inevitably influences e-learning and the overall learning process. The original learning process follows one 
traditional model, wherein an educator and students come together at the same physical location, usually in the classroom, and the educator leads the learning process.

\section{Methodology}

This section is described design of the research, participants, instruments, data collection and data analysis.

\section{Design of the research}

This research designed intervention strategies which were tested by analyzing the intention of the users. This study combined the application of persuasion strategies with a survey scale that explains factors that can increase the intention of users. Behavior changes target is carried out by comparing the initial assessment of behavior with the final assessment. Comparison of the condition of the initial behavior and the condition of the final behavior was made to explain changes in behavior that occurred.

\section{Participants}

Data were taken in a homogeneous community and a specific scope. Testing the effect of behavior change was carried out in a test class consisting of 30 students. The test class consisted of first-year students at a private polytechnic-based college. Before the application of e-learning, the mapping process was done to see the behavior of previous test participants. Mapping was done by asking the test participants' initial position on the target behavior.

\section{Instruments}

Data were collected by conducting questionnaires to test participants. The acceptance model used in this study was developed from (Widyasari, Nugroho, \& Permanasari, 2017). In this model, many variables affected the intention. The independent variables also derived from (Widyasari et al., 2017). The hypothesis model is shown in Fig. 1.

The questions were adjusted so that they matched the context of the user and the persuasion aspects. The independent variable of the user intent was assessed on a 5-point scale, where 1-strongly agree, 2-agree, 3-neutral, 4-disagree, and 5-strongly disagree. The survey was conducted before and after the intervention. This research uses Smart PLS 3 to process data, analyze and test the relevance of construct variables. Behavior change before and after intervention analyzed with nonparametric analysis method Wilcoxon Signed-Rank for paired data differences.

\section{Data collection}

The mapping also considered the experience of internet usage and learning media in the past. Mapping test participants in a group of behaviors were classified into four types. A first group is a group that does not understand and never used it, the second group is a group that does understands but never use it, a third group is a group that understands and sometimes uses it, and a fourth group is a group that understands and uses it regularly.

Grouping was done by giving direct questions to test participants regarding the habits of accessing the internet, features, and systems that are directly related to information technology in learning. After the grouping stage, the persuasive 


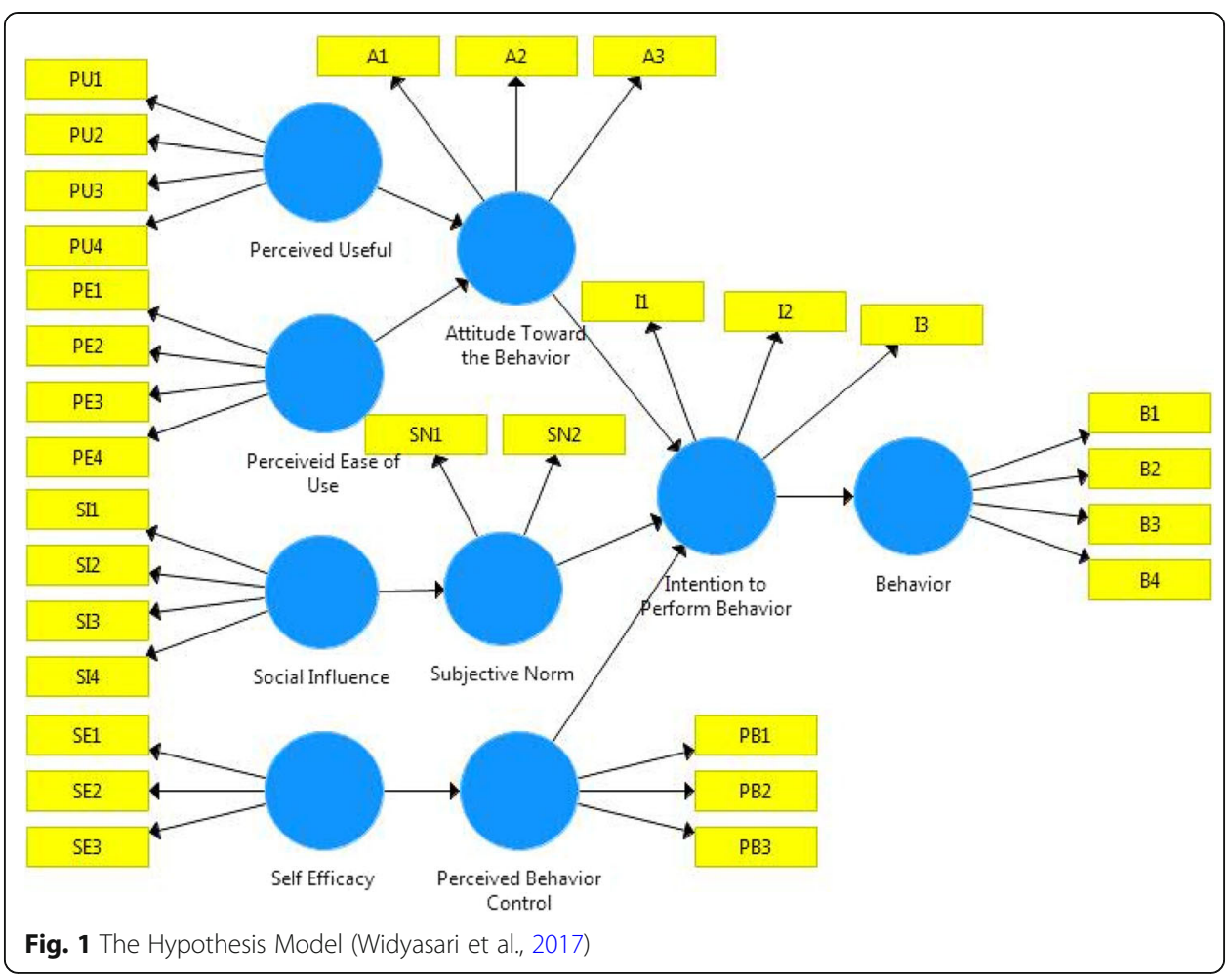

technology must be accepted and adopted. Therefore we persuaded the users (the students). The stages of change in persuasive action from a behavioral point of view were defined differently. According to Geller's model of behavioral change (Yun, Scupelli, Aziz, \& Loftness, 2013), there are four stages of change and three types of interventions. Each stage of change can work well if an intervention is carried out. There are three types of intervention in the Geller model, namely instructional, motivational, and supportive interventions.

The instructional intervention is done by providing an understanding of behavior in the form of education, advice, and self-monitoring. Meanwhile, the motivational intervention focuses on comparing behavioral performance that is targeted and building commitment in the form of user engagement. Engagement is very important for success in any intervention including understanding its role in organizational settings (Foster, Lawson, Wardman, Blythe, \& Linehan, 2012).

\section{Data analysis}

Testing was done on a class of 30 people. The application of Web 2.0-based e-learning system with persuasive features needed the change phase. The hypothesis model in this class was tested using Smart-PLS 3 software. The mapping result shows that $53 \%$ of the participants never used e-learning technology before and $47 \%$ of participants had used and understood the use of e-learning.

Outer model analysis of reflective indicator models included analysis on the results of individual item reliability, internal consistency or construct reliability, average variance extracted, and discriminant-validity. Measurement of individual item reliability, internal consistency or construct reliability was categorized into convergent validity. The value of convergent validity measures the amount of correlation between constructs and 


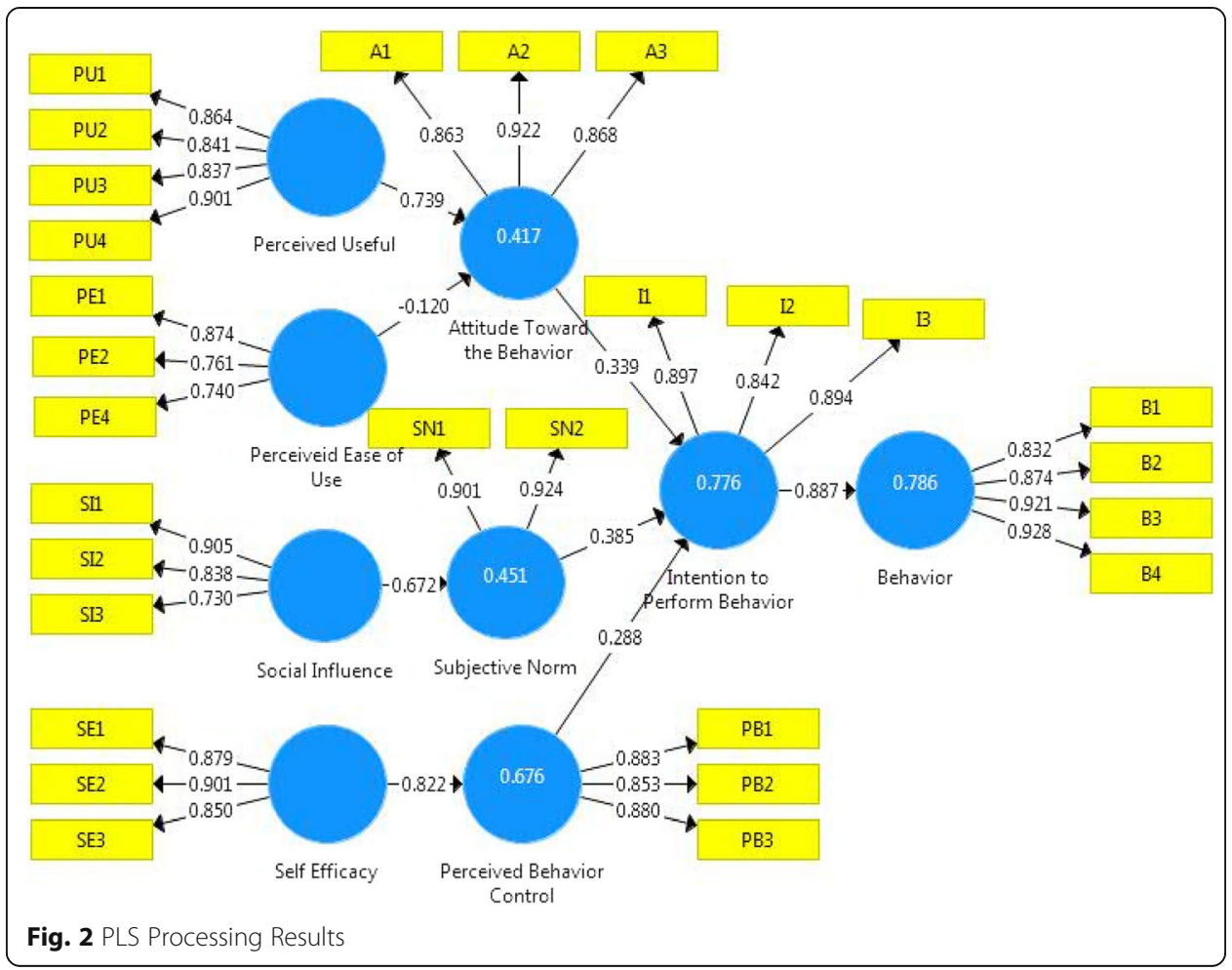

other variables. The value of individual item reliability was obtained from the value of the loading factor. The loading factor value that is greater than 0.7 is considered ideal, which means that the indicator is valid to measure the contract. PLS algorithm processing dan bootstrapping results are displayed in Fig. 2 and Fig. 3.

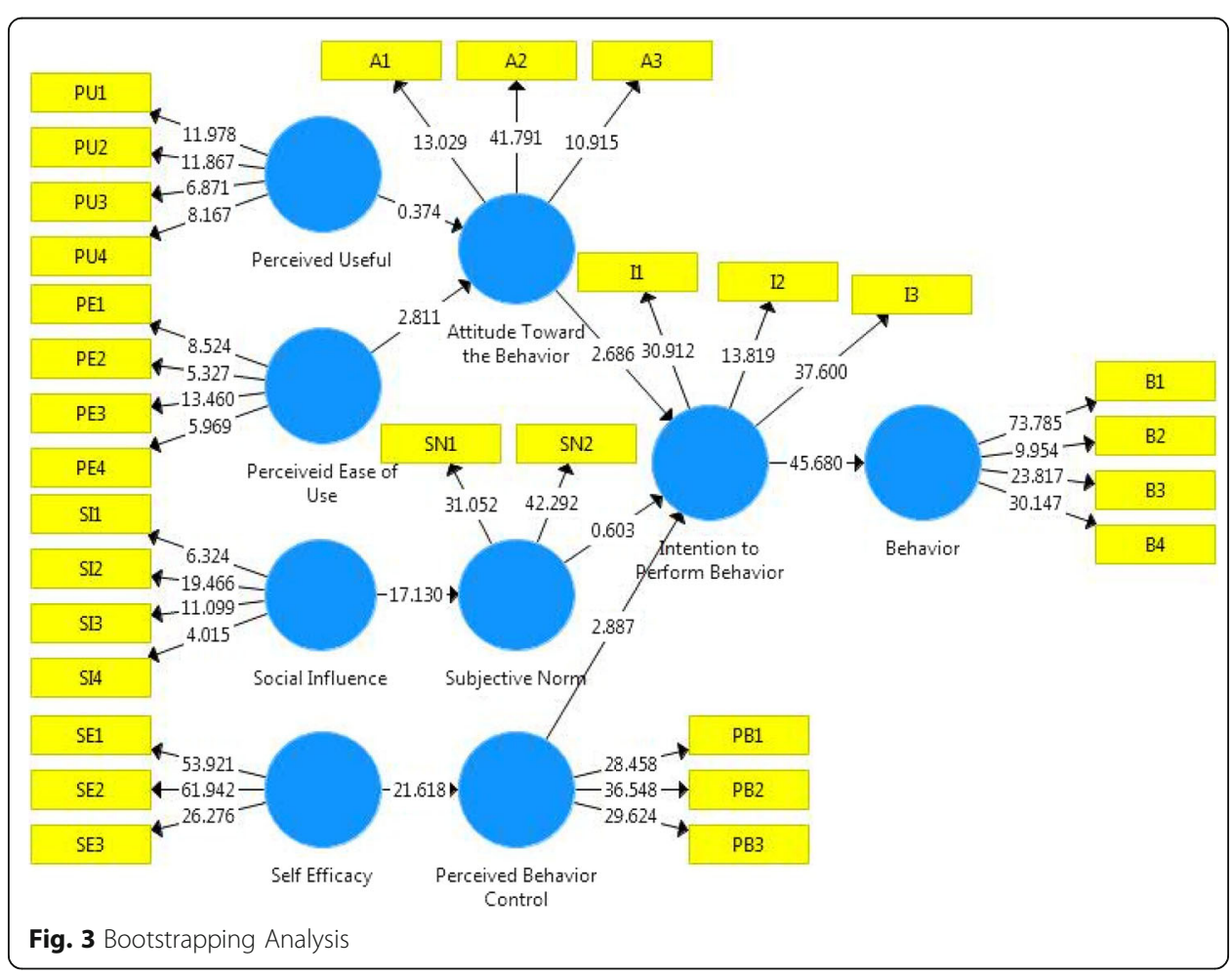


Table 1 AVE, Cronbach's Alpha and composite reliability

\begin{tabular}{lllll}
\hline & AVE & AVE Square & Cronbach's Alpha & Composite Reliability \\
\hline Perceived Useful & 0.7415 & 0.8611 & 0.8842 & 0.9197 \\
Perceived Ease Of Use & 0.5688 & 0.7542 & 0.7415 & 0.8357 \\
Attitude Toward to Behavior & 0.7822 & 0.8844 & 0.8603 & 0.9150 \\
Social Influence & 0.6851 & 0.8277 & 0.7748 & 0.8663 \\
Subjective Norm & 0.8329 & 0.9127 & 0.8003 & 0.9089 \\
Self Efficacy & 0.7695 & 0.8772 & 0.8504 & 0.9092 \\
Perceived Behavior Control & 0.7606 & 0.8721 & 0.8427 & 0.9050 \\
Intention to Perform Behavior & 0.7708 & 0.8779 & 0.8517 & 0.9097 \\
Behavior & 0.7911 & 0.8894 & 0.9113 & 0.9379 \\
\hline
\end{tabular}

Table 2 Path Coefficient, $t$-value and $p$-value

\begin{tabular}{|c|c|c|c|c|c|}
\hline Path & $\begin{array}{l}\text { Path } \\
\text { Coefisien }\end{array}$ & t-value & $\begin{array}{l}p- \\
\text { value }\end{array}$ & $\begin{array}{l}\text { T table } a=0.05 \\
\mathrm{df}=29\end{array}$ & Decision \\
\hline $\begin{array}{l}\text { Attitude Toward to Behavior } \rightarrow \text { Intention to } \\
\text { Perform Behavior }\end{array}$ & 0.3392 & 1.9414 & 0.0527 & 0.1699 & Significant \\
\hline Intention to Perform Behavior $\rightarrow$ Behavior & 0.8865 & 15.8257 & 0.0000 & & Significant \\
\hline $\begin{array}{l}\text { Perceived Behavior Control } \rightarrow \text { Intention to } \\
\text { Perform Behavior }\end{array}$ & 0,2876 & 21,891 & 0.0291 & & Significant \\
\hline $\begin{array}{l}\text { Perceived Ease of Use } \rightarrow \text { Attitude Toward to } \\
\text { Behavior }\end{array}$ & -0.1204 & 0.4750 & 0.6600 & & $\begin{array}{l}\text { Not } \\
\text { Significant }\end{array}$ \\
\hline $\begin{array}{l}\text { Perceived Useful } \rightarrow \text { Attitude Toward to } \\
\text { Behavior }\end{array}$ & 0.7391 & 2.8655 & 0.0043 & & Significant \\
\hline Self Efficacy $\rightarrow$ Perceived Behavior Control & 0.8220 & 12.4661 & 0.0000 & & Significant \\
\hline Social Influence $\rightarrow$ Subjective Norm & 0.6719 & 6.1516 & 0.0000 & & Significant \\
\hline $\begin{array}{l}\text { Subjective Norm } \rightarrow \text { Intention to Perform } \\
\text { Behavior }\end{array}$ & 0.3846 & 2.6153 & 0.0124 & & Significant \\
\hline
\end{tabular}

Table 3 Comparision of behavior "before" and "after"

\begin{tabular}{llllll}
\hline No Responden & "Before" & "After" & No Responden & "Before" & "After" \\
\hline 1 & 2 & 2 & 16 & 3 & 3 \\
2 & 1 & 2 & 17 & 2 & 3 \\
3 & 2 & 3 & 18 & 1 & 1 \\
4 & 2 & 3 & 19 & 3 & 3 \\
5 & 3 & 4 & 20 & 3 & 3 \\
6 & 4 & 4 & 21 & 2 & 3 \\
7 & 1 & 3 & 22 & 3 & 3 \\
8 & 2 & 3 & 23 & 3 & 2 \\
9 & 3 & 3 & 24 & 2 & 3 \\
10 & 3 & 3 & 25 & 3 & 4 \\
11 & 2 & 3 & 26 & 2 & 3 \\
12 & 4 & 4 & 27 & 4 & 4 \\
13 & 1 & 3 & 29 & 1 & 3 \\
14 & 1 & 4 & 30 & 1 & 4 \\
15 & 3 & & & & 4 \\
\hline
\end{tabular}




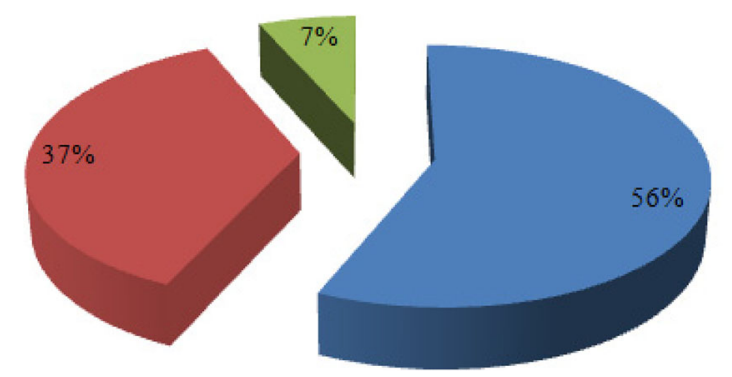

decreased level

same level

improved level

Fig. 4 Distribution of Behavior Level Change

Discriminant validity of the reflective model was evaluated through a cross-loading compared to the square root of AVE. The size of the cross-loading was used to compare the correlation indicator with the contract and the construct of other variables. If the value of cross loading a variable on the variable itself is greater than the value of cross loading on other variables, then this indicates that the variable is able to predict the variable rather than other variables. The value of discriminant validity was considered sufficient if the root value of AVE for each construct was higher than the latent variable correlation value. Value of AVE, Cronbach's Alpha and composite reliability showed in Table 1. Result of Path Coefficient, $t$-value and $p$-value is displayed in Table 2.

The comparison results of the conditions of change on the participants show that not all participants experienced a positive change or leveled up their behavior. The distribution of all participants in Table 3 shows that out of 30 respondents in the test class, there were two respondents with a decreased level of behavior, 11 respondents remained the same, and 17 respondents improved their behavior. The distribution is displayed in Fig. 4.

Based on the output in Table 4, the mean "Before" is 2.3 while the mean "After" the amount is 3.1333 so the difference is 0.8333 . The difference obtained positively means that the data before the intervention has a smaller average than after the intervention.

The correlation between the two before and after data in Table 5, shows that the significance value is 0.319 which is higher than 0.05 so that it can be stated that there is no relationship between the previous data and the after data.

\section{Finding}

\section{Design of technological intervention based on web 2.0 contextual model}

The use and use of technology to improve the workings of humans have been carried out in various fields. In particular, it is called persuasive technology if the use of technology is intended to influence and change the behavior and attitudes of its users.

Table 4 Descriptive Statistics

\begin{tabular}{llllll}
\hline & & Mean & N & Std. Deviation & Std. Error Mean \\
\hline Pair 1 & "Before" & 2,3000 & 30 & 0,95231 & 0,17387 \\
& "After" & 3,1333 & 30 & 0,73030 & 0,13333 \\
\hline
\end{tabular}

Table 5 Paired Samples Correlations

\begin{tabular}{lllll}
\hline & & $N$ & Correlation & Significant \\
\hline Pair 1 & "Before" \& "After" & 30 & 0,188 & 0,319 \\
\hline
\end{tabular}




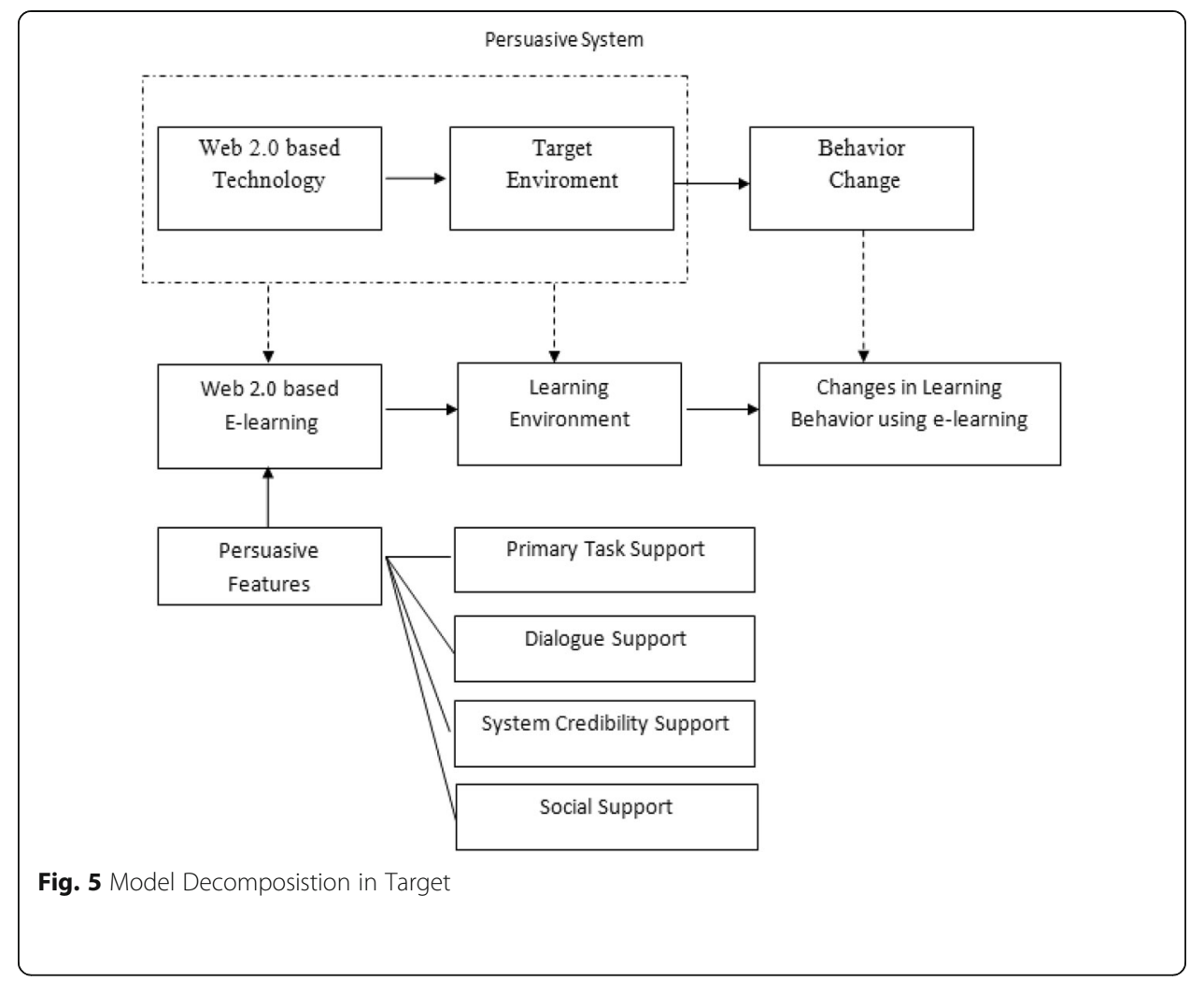

There are several impacts that can occur in the use of Web 2.0-based technology. One of them is that web 2.0 opens up opportunities or new ways for users to communicate and community. Web 2.0 as a persuasive technology combine concept computer-human and computer persuasion.

One information technology that supports a persuasive system is a behavior change support system (BCSS). Behavior change support systems (BCSS) are defined as information systems designed to form, change, strengthen one's attitudes, behavior, and

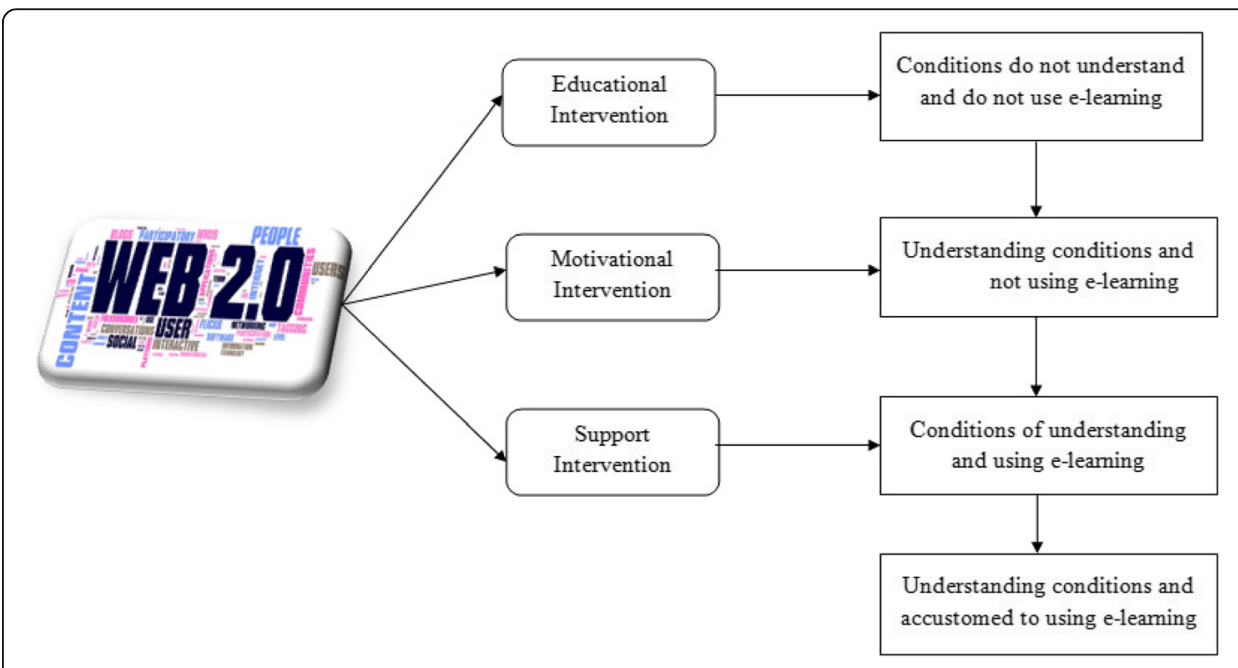

Fig. 6 Behavior Enviroment and the Conducted Intervention 
Table 6 Tests of Normality

\begin{tabular}{llrr}
\hline & \multicolumn{2}{c}{ Shapiro-Wilk } & df \\
\cline { 2 - 4 } & Statistic & 30 & Significant \\
\hline Difference & 0,892 & 0,005 \\
\hline
\end{tabular}

compliance without committing fraud, coercion, or threats to achieve goals. There are three stages and three different objectives proposed in the BCSS concept. A person's behavior needs to be formulated, changed, and strengthened to fulfill the rules (Oinas-Kukkonen, 2013). The assessment of the initial conditions of behavior to be intervened needs to be defined at the beginning of the persuasion process so that the target behavior is clearer and can be achieved.

The conceptual model in (Widyasari, Nugroho, \& Permanasari, 2018) was used in the context of the learning process. The persuasive focus was applied through Web 2.0 technology tailored to the target environment and desired behavior changes. The description of the intervention model decomposition in the target environment can be seen in Fig. 5.

Increased motivation can only change behavior for a while; thus, a continuous intervention is needed to support a person to maintain his behavior. This type of intervention is called a supportive intervention. This type of intervention is done by communicating in social communication media, providing media or control devices, and giving rewards for the targeted behavior.

The intervention model in this study used Web 2.0 technology. The relationship of interaction with the expected behavioral conditions is illustrated in Fig. 6 . Based on the proposed intervention model, the persuasive concept of the system and changes in Geller's behavior, a model for implementing Web 2.0 technology in e-learning was developed for the learning process.

Before using analyzing, the following hypothesis is set:

Ho: The level of understanding of users before and after using e-learning technology based on persuasive technology is the same.

H1: The level of understanding before and after using e-learning technology based on persuasive technology is not the same.

For paired data analysis, data normality information is needed. This is needed to determine the analysis method to be used. Data normality analysis used is Shapiro-Wilk because the amount of data is less than 50 .

Table 7 Rank

\begin{tabular}{lllrr}
\hline & & N & Mean Rank & Sum of Ranks \\
\hline "After"-"Before" & Negative Ranks & $2^{\mathrm{a}}$ & 6,50 & 13,00 \\
& Positive Ranks & $17^{\mathrm{b}}$ & 10,41 & 177,00 \\
& Ties & $11^{\mathrm{c}}$ & & \\
& Total & 30 & & \\
& & & & \\
\end{tabular}


Table 8 Wilcoxon Signed-ranks Test

\begin{tabular}{ll}
\hline & "After"- "Before" \\
\hline$Z$ & $-3,405^{\text {a }}$ \\
Asymptotic significance (2-tailed) & 0,001 \\
\hline
\end{tabular}

${ }^{a}$ based on negative ranks

Based on the results of the normalization analysis in Table 6, it is known that the data is not normal because the significant value is 0.005 or less than $\alpha=0.05$. For abnormal data, a nonparametric analysis of the Wilcoxon Signed-rank test can be used to analyze paired data differences.

Based on the Wilcoxon signed-rank test in Tables 7 and 8, there were significant differences in the level of understanding between before using e-learning based persuasive technology and after it $(\mathrm{Z}=3.405 p=0.001)$. Value $\mathrm{Z}$ means that there are significant differences between the data before getting persuasive technology intervention and data after getting persuasive technology intervention.

\section{Discussion}

This research was developed from (Anderson, 2012; Ritterband, Thorndike, Cox, Kovatchev, \& Gonder- Frederick, 2009) in the context of the learning process and using web 2.0. Web 2.0 as a social technology used in interventions focuses more on ease of access for persuader and persuadee. Behavioral changes that were targeted at the use of Web 2.0-based e-learning were very simple but were carried out specifically. It created a picture of the desired change effect. The experience of the test participants was mapped to depict the initial and targeted behavior. The impact and relevance of research on the development and effectiveness of intervention models proposed within the scope of existing technology intervention models. Internet intervention models and technology in general already exist and are widely used, especially those related to behavioral changes in the health sector (Ritterband et al., 2009). Web 2.0 as a social technology used in interventions focuses more on ease of access for those who influence (persuader) and for those who are influenced (persuadee). The use of web 2.0 in influencing its users has been used in marketing and advertising (Gagliardi, 2013).

The intervention model is related to persuasion because involvement and participation in collaboration were aspects that were developed in this study. Using web 2.0 directly in an educational environment is not an easy thing to do. Many components must be considered such as the purpose of use, the context, the users, the type of educational environment, policies and rules including government regulations. In this research, web 2.0 was not applied directly but was embedded in e-learning technology. Web 2.0-based e-learning developed also uses persuasion features. The use of persuasion features to emphasize the persuasion process that is carried out using web 2.0 capabilities as a social technology.

The intervention model was focused more on the involvement of the users of web 2.0 in the intervention process. The intervention model was simulated in the learning process conducted by the teacher (persuader) and students (persuaded) by Web 2.0-based e-learning technology. After understanding the features of Web 2.0 technology that can be used to change behavior, the Web 2.0 technology was adjusted to be both used directly and in the 
development of other systems. In this study, web technology was used in e-learning technology developed by placing features and capabilities of social interaction in e-learning technology.

Every proposed strategy depends on the context and scope of its implementation. The feature of persuasion in principle can be applied to all fields, but it still depends on the objective of persuasion to be achieved. Not all features and ways of persuasion in the system can support the achievement of the persuasion objectives. Web 2.0 technology that was integrated into the persuasion technology used in this study was adopted using the TOE framework in educational organizations and analyzed for its effectiveness in social system schemes. The TOE framework was used specifically as an adoption approach to providing scope limitations and the context of persuasion to be carried out. Web 2.0 technology integrated into the persuasion technology was analyzed for its usefulness level in the TOE framework. In this case, Web 2.0 technology was not used directly in an existing learning process but it was integrated with e-learning technology.

The e-learning technology used in educational organizations to help improve the teaching and learning process has three levels, namely as an addition, assistance, or substitute. The aspects of acceptance and adoption at each of these levels should be the basis for determining the features and methods of persuasion used in the technology.

Characteristics and availability of e-learning technology in the teaching and learning process are supported and needed in the business process of higher education. The factor of the recipient environment, namely the universities and stakeholders, provides an opportunity to use e-learning, even though not all universities use it $100 \%$ or as a substitute of the conventional learning process. The management of an organization and higher

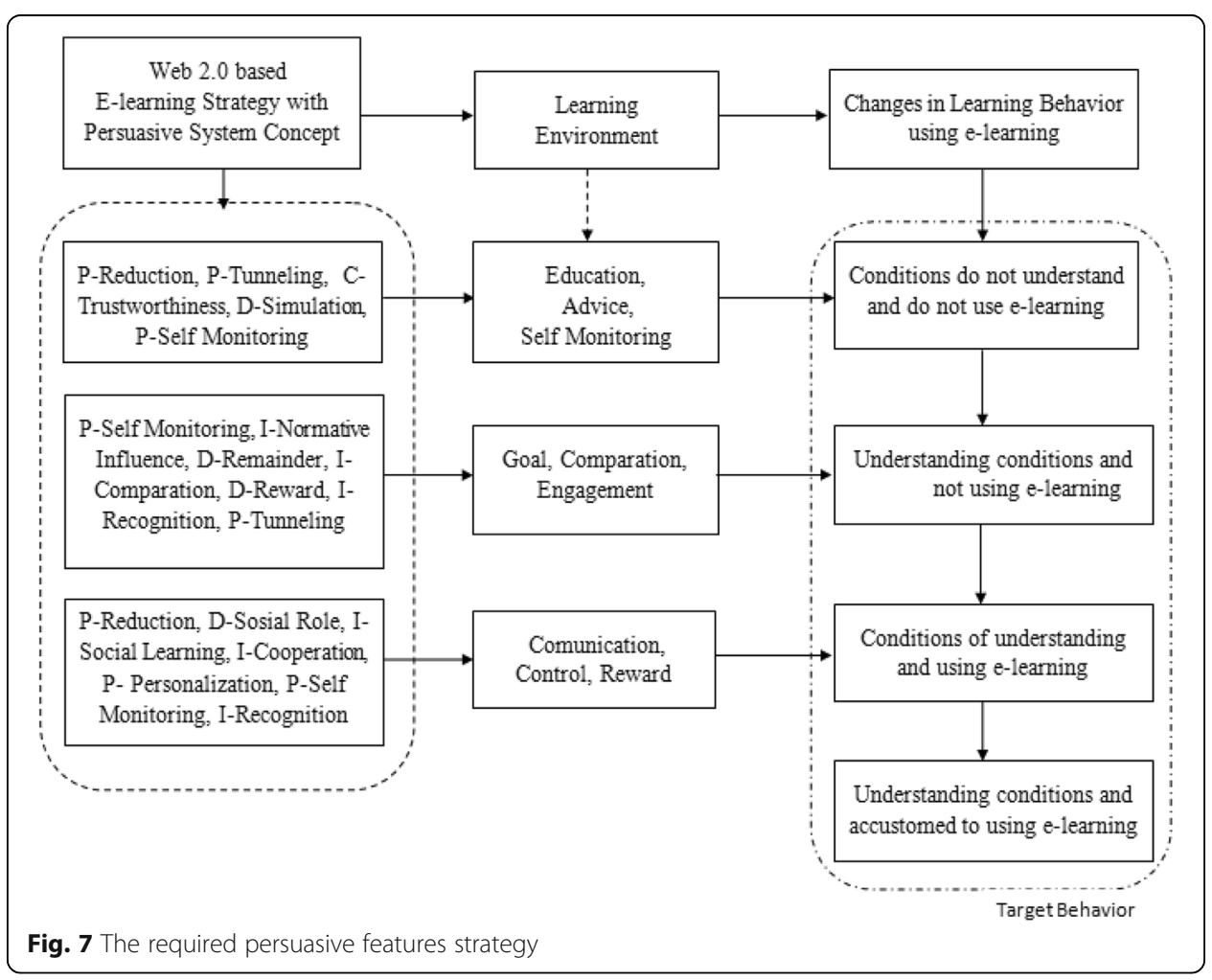


education also support the use of technology, even though the level of implementation is not the same for each university.

Organizational factors are used to analyze the connection of Web 2.0 technology with formal and informal structures of environments/user groups or organizations at large. The teaching and learning process contains a relationship between the teacher and the students. Building non-formal relationships outside the teaching and learning process will be useful for formal relationships.

The size of the group/community or the organization and the communication process that is carried out with the use of Web 2.0 technology will be more open, even though formal and non-formal boundaries are uncertain. Organizational problems and weaknesses, such as communication between teachers and students, are accommodated in e-learning media. The chat feature is expected to provide a medium of communication to ask questions directly without having to meet face to face.

This study presented a concept of persuasive intervention that can be adjusted and modified in various types of information technology with the concept of Web 2.0. The context, the scope, and objectives of persuasion are the initial aspects of the development of that can be specified into an intervention model. The concept of user involvement in Web 2.0 is the main impetus for the proposed intervention model. The emerging persuaders are developed from the persuadee involved in a system.

The targeted behavioral changes are important to be defined at the beginning of the intervention. The used persuasion strategy is a strategy that is carried out directly by the participants but later replaced by the persuader in the system. The system is more stable in carrying out persuasion on its users because it does not have an emotional or human connection. The developed system does not sort features based on personal and user position but can be used by all users at any level.

This study utilized a technology used in educational organizations but with Web 2.0 features and concepts. Other studies have introduced the Web 2.0 technology as a medium of intervention but they have not provided strategic direction for the application of certain behaviors (Anderson, 2012). Target behavior was defined before determining the strategy to be used. Persuasion strategies in the learning environment were then derived from the persuasive context as in Fig. 7.

\section{Conclusions}

Behavioral changes that are defined at the beginning of the persuasion process are carried out specifically to observe the changes. The varied students' environment requires different methods or features of persuasion. Behavioral changes observed with the use of e-learning with persuasion features show that not all behaviors change in a positive direction. This result can also occur in the human to human persuasion, but with the system, the method of persuasion can be easily changed. It is different from the conventional persuasion by technology or computers, where the features of persuasion are always consistent in influencing the users even though the user (persuadee) rejects it. Consistency is one advantage of persuasive technology.

The universal use of Web 2.0 technology brings a very diverse set of features; hence, the persuadee may not realize it. In Web 2.0 technology, the persuader is the Web 2.0 users or a person who's been a part of the persuadee group. Involvement in collaborating and sharing within a connected environment that is anywhere and anytime is interesting to be 
observed. The use in a formal environment or group and organization will be blurred with the use in non-formal environments.

\section{Acknowledgements}

Thank you to all respondents who spent their time and Kemenristek Dikti who funded data collection.

\section{Funding}

Data collection is funded by Kemenristek Dikti as part of the doctoral program scholarship.

\section{Availability of data and materials}

The data used are the results of questionnaires on respondents. Complete data is attached to supplementary material.

\section{Authors' contributions}

This research is part of a dissertation research conducted by the first authors and other authors as promotor and copromotor. All authors read and approved the final manuscript.

\section{Competing interests}

The authors declare that they have no competing interests.

\section{Publisher's Note}

Springer Nature remains neutral with regard to jurisdictional claims in published maps and institutional affiliations.

\section{Author details}

${ }^{1}$ Electrical and Information Technology Engineering Departement, Universitas Gadjah Mada, Yogyakarta 55281, Indonesia. ${ }^{2}$ Information Technology Departement, Politeknik Caltex Riau, Pekanbaru 28261, Indonesia.

Received: 26 September 2018 Accepted: 21 March 2019

Published online: 30 April 2019

\section{References}

Admiraal, W., \& Lockhorst, D. (2009). E-learning in small and medium-sized enterprises across Europe: Attitudes towards technology, learning and training. International Small Business Journal, 27(6), 743-767. https://doi.org/10.1177/ 0266242609344244 .

Anderson, I. J. R. (2012). Web 2.0 tools as interventions for training and performance improvement. Capella University https://dl. acm.org/citation.cfm?id=2518933.

Batsila, M., Tsihouridis, C., Vavougios, D., \& loannidis, G. (2015). Factors that influence the application of web 2.0 based techniques for instructional purposes-a case study. International Journal of Emerging Technologies in Learning, 10(4), 1521 https:/www.researchgate.net/profile/Charilaos_Tsihouridis/publication/283879719_Factors_that_Influence_the_ Application_of_Web_20_Based_Techniques_for_Instructional_Purposes___A_Case_Study/links/ 59065a54aca272116d332fe8/Factors-that-Influence-the-Application-of-Web-20-Based-Techniques-for-InstructionalPurposes-A-Case-Study.pdf.

Chua, F. F., \& Tay, E. S. (2012). Developing virtual learning environment 2.0 using web services approach. In Advanced learning technologies (ICALT) international conference on IEEE, 12th, (pp. 230-234). https://doi.org/10.1109/ICALT.2012.37.

Davis, I. (2005). Talis, web 2.0 and all that. Internet alchemy blog, 4 July 2005. http://blog.iandavis.com/2005/07/talis-web-2-0and-all-that/. Accessed 16 Apr 2018

Fogg, B. J. (2009). A behavior model for persuasive design. In International conference on persuasive technology, 4th, (p. 40). https://doi.org/10.1145/1541948.1541999.

Foster, D., Lawson, S., Wardman, J., Blythe, M., \& Linehan, C. (2012). Watts in it for me?: design implications for implementing effective energy interventions in organisations. In Conference on human factors in computing systems, (pp. 2357-2366). https://doi.org/10.1145/2207676.2208396.

Gagliardi, D. (2013). Next generation entrepreneur: Innovation strategy through web 2.0 technologies in SMEs. Technology Analysis \& Strategic Management, 25, 891-904. https://doi.org/10.1080/09537325.2013.823151.

Gavin, D., Baxter, J., Baxter, G. J., \& Connolly, T. M. (2014). Implementing web 2.0 tools in organisations: Feasibility of a systematic approach. The Learning Organization, 21(1), 6-25. https://doi.org/10.1108/TLO-08-2013-0042.

Inamorato dos Santos, A., \& Punie, Y. (2016). Opening up education: A support framework for higher education institutions. Seville: Joint Research Centre. https://doi.org/10.2791/293408 http://publications.jrc.ec.europa.eu/repository/bitstream/ JRC101436/jrc101436.pdf.

Kim, H. J., \& Kim, Y. (2016). Design of e-teaching portfolio system framework for e-tutor competency management. International Journal on Advanced Science, Engineering and Information Technology, 8(1), 192-198. https://doi.org/10. 18517/ijaseit.8.1.2699.

Kim, J. H. (2017). Smartphone-mediated communication vs. face-to-face interaction: Two routes to social support and problematic use of smartphone. Computers in Human Behavior, 67(2017), 282-291. https:/doi.org/10.1016/j.chb.2016.11.004.

Mason, R., \& Rennie, F. (2007). Using web 2.0 for learning in the community. The Internet and Higher Education, 10(3), 196-203. https://doi.org/10.1016/j.iheduc.2007.06.003.

Mitra, S., \& Roy, S. (2016). Web 2.0 technologies and Indian IT service companies: An impact analysis. In Smart technologies for smart nations, (pp. 73-88). Verlag Singapur: Springer. https://doi.org/10.1007/978-981-287-585-3_6.

Napitupulu, D. (2017). A conceptual model of e-government adoption in Indonesia. International Journal on Advanced Science, Engineering and Information Technology, 7(4), 1471-1478. https://doi.org/10.18517/ijaseit.7.4.2518.

Newman, R., Chang, V. R., Walters, J., \& Wills, G. B. (2016). Web 2.0 - the past and the future. International Journal of Information Management, 36(4), 591-598. https://doi.org/10.1016/j.jijnfomgt.2016.03.010. 
Oinas-Kukkonen, H. (2013). A foundation for the study of behavior change support systems. Personal and Ubiquitous Computing. https://doi.org/10.1007/s00779-012-0591-5.

Oinas-Kukkonen, H., \& Harjumaa, M. (2009). Persuasive systems design: Key issues, process model, and system features. Communications of the Association for Information Systems, 24(1), 28. https://doi.org/10.17705/1CAls.02428.

Ritterband, L. M., Thorndike, F. P., Cox, D. J., Kovatchev, B. P., \& Gonder- Frederick, L. A. (2009). A behavior change model for internet interventions. Annals of Behavioral Medicine, 38, 18-27. https://doi.org/10.1007/s12160-009-9133-4.

Seely Brown, J., \& Adler, R. P. (2008). Open education, the long tail, and learning 2.0. Educause Review, 43(1), 16-20.

Shipps, B. (2013). Social networks, interactivity and satisfaction: Assessing socio-technical behavioral factors as an extension to technology acceptance. Journal of Theoretical and Applied Electronic Commerce Research, 8(1), 35-52. https://doi.org/10. 4067/S0718-18762013000100004.

Simoes, L., \& Borges Gouveia, L. (2008). Web 2.0 and higher education: Pedagogical implications. Global University Network for Innovation https://upcommons.upc.edu/bitstream/handle/2099/5736/12_pap_Simoes.pdf. Accessed 16 Apr 2018.

Sivarajah, U., Irani, Z., \& Weerakkody, V. (2015). Evaluating the use and impact of web 2.0 technologies in local government. Government Information Quarterly, 32(4), 473-487. https://doi.org/10.1016/j.giq.2015.06.004.

Wang, M. (2011). Integrating organizational, social, and individual perspectives in web 2.0-based workplace e-learning. Information Systems Frontiers, 13(2), 191-205. https://doi.org/10.1007/s10796-009-9191-y.

Widyasari, Y. D. L., Nugroho, L. E., \& Permanasari, A. E. (2017). Persuasiveness web 2.0 in behavioral intention: A conceptual model. In International conference on sustainable information engineering and technology (SIET), (pp. 117-122). https://doi. org/10.1109/SIET.2017.8304120.

Widyasari, Y. D. L., Nugroho, L. E., \& Permanasari, A. E. (2018). Technology web 2.0 as intervention media: Technology organization environment and socio-technical system perspective. In International conference on information technology and electrical engineering (ICITEE), 10th, (pp. 124-129). https://doi.org/10.1109/ICITEED.2018.8534744.

Yadav, R., Tiruwa, A., \& Suri, P. K. (2017). Internet based learning (IBL) in higher education: A literature review. Journal of International Education in Business, 10(2), 102-129. https://doi.org/10.1108/JEB-10-2016-0035.

Yun, R., Scupelli, P., Aziz, A., \& Loftness, V. (2013). Sustainability in the workplace: Nine intervention techniques for behavior change. In International conference on persuasive technology, (pp. 253-265). https://doi.org/10.1007/978-3-642-37157-8_30.

Zeng, S., Gonzalez, J., \& Lobato, C. (2015). The effect of organizational learning and web 2.0 on innovation. Management Decision, 53(9), 2060-2072. https://doi.org/10.1108/MD-06-2014-0388.

\section{Submit your manuscript to a SpringerOpen ${ }^{\circ}$ journal and benefit from:}

- Convenient online submission

- Rigorous peer review

- Open access: articles freely available online

- High visibility within the field

- Retaining the copyright to your article

Submit your next manuscript at $\boldsymbol{\nabla}$ springeropen.com 